Article

\title{
Cracking the Initiation Mechanism of High Cu-Bearing Nitrogen-Alloyed Austenitic Stainless Steel in the Process of Hot Deformation
}

\author{
Xiao-Yang Fu ${ }^{1,2}$, Pu-Cun Bai ${ }^{1, *}$ and Ji-Chun Yang ${ }^{2}$ \\ 1 School of Material Science and Engineering, Inner Mongolia University of Technology, Hohhot 010051, \\ China; fxy9195@163.com \\ 2 School of Material and Metallurgy, Inner Mongolia University of Science and Technology, Baotou 014010, \\ China; yangjichun1963@163.com \\ * Correspondence: pcbai@imut.edu.cn; Tel.: +86-471-657-7053
}

Received: 6 September 2018; Accepted: 4 October 2018; Published: 11 October 2018

\begin{abstract}
The cracking initiation mechanism of high Cu-bearing nitrogen-alloyed austenitic stainless steel was systematically investigated by using a Gleeble-1500D simulator under different strains and deformation temperatures in the hot deformation process. The cracking initiation process and microstructure variations were characterized by optical microscopy (OM), X-ray diffraction (XRD), field emission scanning electron microscopy (FESEM) with energy dispersive spectroscopy (EDS) and transmission electron microscopy (TEM). In the deformation process, $\mathrm{Cu}$-rich and $\mathrm{Cr}$-rich phases were found around the microscopic crack at the strain of 0.5 . Cu content was found to be higher at the grain boundary than inside the grain. The equilibrium phase diagram calculated by Thermo-calc shows that $\mathrm{Cu}$ precipitates out in the form of an elementary substance below $1022^{\circ} \mathrm{C}$, when the $\mathrm{Cu}$ mass fraction reaches $5 \%$. Meanwhile, dislocation walls and twin crystals were observed by TEM. The results show that the synergistic effect of the secondary phases, such as $\mathrm{M}_{23} \mathrm{C}_{6}$ precipitated along the grain boundary and stress concentration, lead to crack generation, which is lower at high temperature and low temperature and is higher at $1100{ }^{\circ} \mathrm{C}$ and increase as the strain increases.
\end{abstract}

Keywords: Cu-bearing; nitrogen-alloyed; austenitic stainless steel; crack; hot deformation

\section{Introduction}

In recent years, Cu-bearing austenite stainless steels have been widely used in dentistry, orthopedics, and other medical applications due to their novel structural and strong antibacterial properties, which have been attributed to the $\mathrm{Cu}$ ions acting as the antibacterial agent $[1,2]$. Moreover, enhancements in the high temperature strength of the steels can be achieved by the formation of tiny $\mathrm{Cu}$-rich phase precipitates with nanometers sizes when an appropriate amount of $\mathrm{Cu}$ element is added in the steel [3]. Some researchers [4,5] have reported that $\mathrm{Cu}$ is often added into steel to improve the corrosion resistance and creep resistant strength. The mechanism of the enhancement and the role of $\mathrm{Cu}$ in the steel are yet to be identified and are currently under investigation $[6,7]$. However, it has been proposed that $\mathrm{Cu}$, which is dissolved in the austenite matrix during the solution treatment, precipitates during service as a nano-sized $\mathrm{Cu}$-rich phase within the matrix [8]. Yang et al. [9] have revealed that the addition of $\mathrm{Cu}$ up to $3-4 \mathrm{wt} . \%$ is optimum because such addition leads to the appearance of $\mathrm{Cu}$-rich phase precipitates with an ideal combination of size, number and spacing and accelerates the effect of $\mathrm{Cu}$ on the enhancement of the creep performance of steel. The excessive addition of copper to steels can also have adverse effects on mechanical properties. It can form low-temperature eutectic phases that preferentially segregate to the grain boundaries and embrittle the alloy $[10,11]$. Futamura et al. [12] reported that the addition of up to $4 \mathrm{wt} . \% \mathrm{Cu}$ to low carbon austenitic 
stainless steels leads to a reduction in ductility due to the segregation and precipitation of $\mathrm{Cu}$ along the grain boundaries during solution treatment, which in turn facilitates grain boundary embrittlement. Tong et al. [13] have studied in depth copper precipitation behavior in $4.36 \mathrm{wt}$ \% Cu-bearing austenitic steels by atom probe tomography and confirmed $\mathrm{Cu}$ precipitates present a core-shell structure with a shell enriched in $\mathrm{Ni}, \mathrm{Mn}$ and $\mathrm{Si}$ after the ageing treatment. It has also been shown [14] that the addition of $\mathrm{Cu}$ up to $5 \mathrm{wt}$ \% to SUS $304 \mathrm{H}$ alloys indeed leads to fracture and fatigue crack growth characteristics at ambient conditions.

Numerous studies have been performed on the influence of different $\mathrm{Cu}$ additions on the microstructure, mechanical properties, corrosion resistance, antibacterial performance and fatigue cracks of steel. Hence, in this work, the cracking initiation mechanism of Cu-bearing nitrogen-alloyed austenitic stainless steel in the process of the hot deformation with different temperatures and deformations was studied using a Gleeble-1500D simulator. To elucidate the mechanism, the equilibrium phase diagram of $\mathrm{Cu}$-bearing nitrogen-alloyed austenitic stainless steel was calculated by Thermo-calc. Using field emission scanning electron microscopy (FESEM) and transmission electron microscopy (TEM), the microstructure of the tested alloy was characterized in detail, and the cracking initiation mechanism was investigated.

\section{Experimental Procedures}

Ingots were fabricated using a $50 \mathrm{~kg}$ vacuum induction furnace and were forged and hot rolled at $1200{ }^{\circ} \mathrm{C}$ to obtain $15 \mathrm{~mm}$ thick plates. Subsequently, these plates were solution treated at $1100{ }^{\circ} \mathrm{C}$ for $30 \mathrm{~min}$, followed by water quenching to obtain a homogeneous austenite microstructure. The hot rolled plates were used for various mechanical properties and microstructural investigations. The chemical compositions of the alloy examined in this investigation are as follows (wt.\%): $0.11 \mathrm{C}, 18.7 \mathrm{Cr}, 5.33 \mathrm{Ni}$, 5.15 Cu, 1.86 Mn, 2.12 Mo, 0.27 Si, 0.01 P, 0.008 S, 0.38 N, and Fe balance.

The hot deformation tests were conducted using a Gleeble-1500D simulator (DSI, New York, NY, USA). Cylindrical specimens with a diameter and length of $8 \mathrm{~mm}$ and $12 \mathrm{~mm}$, respectively, were machined from the solution treated plates, and each specimen for which the hot deformation tests were conducted was first heated to $1250{ }^{\circ} \mathrm{C}$ at the rate of $5^{\circ} \mathrm{C} / \mathrm{s}$ and was held for 5 min to obtain the same initial austenitic grain size. After being cooled to the deformation temperature at the rate of $30{ }^{\circ} \mathrm{C} / \mathrm{s}$, and thermally retarded for $30 \mathrm{~s}$, the specimens were subjected to compressive deformation with different deformation values in the $20-40 \%$ range and temperature of $1050-1200{ }^{\circ} \mathrm{C}$ at the strain rate of $1 \mathrm{~s}^{-1}$, as shown in Figure 1, followed by water quenching immediately to preserve the high temperature deformed microstructures.

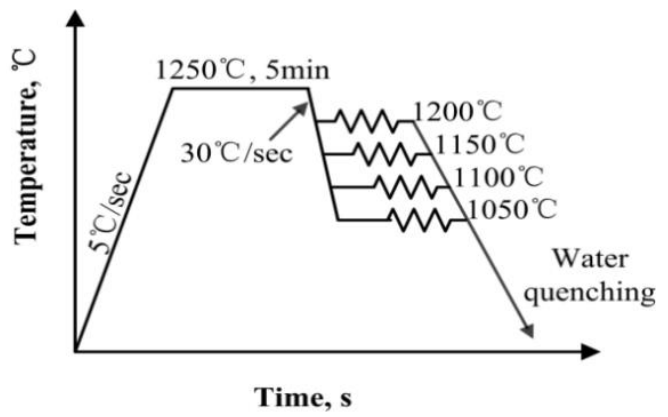

Figure 1. Schematic diagrams of the hot compression test.

To characterize the change in the microstructure, the quenched specimens were sliced in parallel with the compression axis at the center and subjected to standard grinding and polishing techniques prior to etching with a solution of $30 \mathrm{~mL}$ of $\mathrm{HCl}$ and $10 \mathrm{~mL}$ of $\mathrm{HNO}_{3}$ for $30-50 \mathrm{~s}$ at room temperature. The etched samples subjected to different hot compression deformations were then examined using optical microscopy (OM) (ZEISS, Oberkochen, Germany) and scanning electron microscopy (SEM) (FEI, Hillsboro, OR, USA) with energy dispersive spectroscopy (EDS) to evaluate the initiation, growth, 
and propagation process of cracks under different deformation conditions. The microstructure was analyzed by an EBSD system attached to a Zeiss Suppra55 field emission scanning electron microscopy (FESEM) (ZEISS, Oberkochen, Germany). The EBSD specimens were prepared by mechanical grinding, polishing, and subsequent electrolytic polishing in a solution of ethyl alcohol and perchloric acid (15:85, volume fraction) under $20 \mathrm{~V}$ for $30 \mathrm{~s}$. The phase composition in the solution treatment state was identified by $\mathrm{X}$-ray diffraction (XRD) (RIGAKU, Tokyo, Japan) with a $\mathrm{Cu}-\mathrm{K} \alpha$ characteristic radiation source in the $2 \theta$ range of $20-80^{\circ}$. Thin foils were prepared for transmission electron microscopy (TEM). They were observed by using a TEM instrument (JEM2100) (JEOL, Tokyo, Japan) with EDS at $200 \mathrm{kV}$ to investigate the microcosmic mechanism responsible for crack formation during hot compression. In order to prevent the influence of copper, the double tilt test bench is made of Be. Thermodynamic calculations were carried out using Thermo-calc 2017a software for Windows using the TCFE8 database for steels and Fe-base alloys.

\section{Results and Discussion}

\subsection{Thermodynamic Calculation and Microstructure}

Figure 2 shows the equilibrium phase diagram of the tested alloy, where the horizontal axis represents the mass percent of copper, and the vertical axis is the phase transformation temperature. It can be seen that for austenite stainless steel with $\mathrm{Cu}$ added to more than $1.2 \%$, copper precipitates out to different degrees at $692{ }^{\circ} \mathrm{C}$, and the maximum solubility temperature of the elementary $\mathrm{Cu}$ rises gradually with the increase in the copper content. When the mass fraction of the added $\mathrm{Cu}$ in the material reaches $5 \%$, the maximum solubility temperature is $1022^{\circ} \mathrm{C}$, at which point the stability region of austenite stainless steel is between $1022^{\circ} \mathrm{C}$ and $1323^{\circ} \mathrm{C}$, and the microstructure is mainly austenite. When the mass fraction is $6.4 \%$, the maximum solubility temperature is $1087^{\circ} \mathrm{C}$ and stays unchanged. Meanwhile, the maximum solubility temperature of $\mathrm{Cr}_{2} \mathrm{~N}$ rises with the increase mass fraction of $\mathrm{Cu}$, and the maximum solubility temperature of $\mathrm{Cr}_{2} \mathrm{~N}$ is $1328{ }^{\circ} \mathrm{C}$ at $5 \% \mathrm{Cu}$. However, the austenite zone vanishes when $8.4 \% \mathrm{Cu}$ is added.

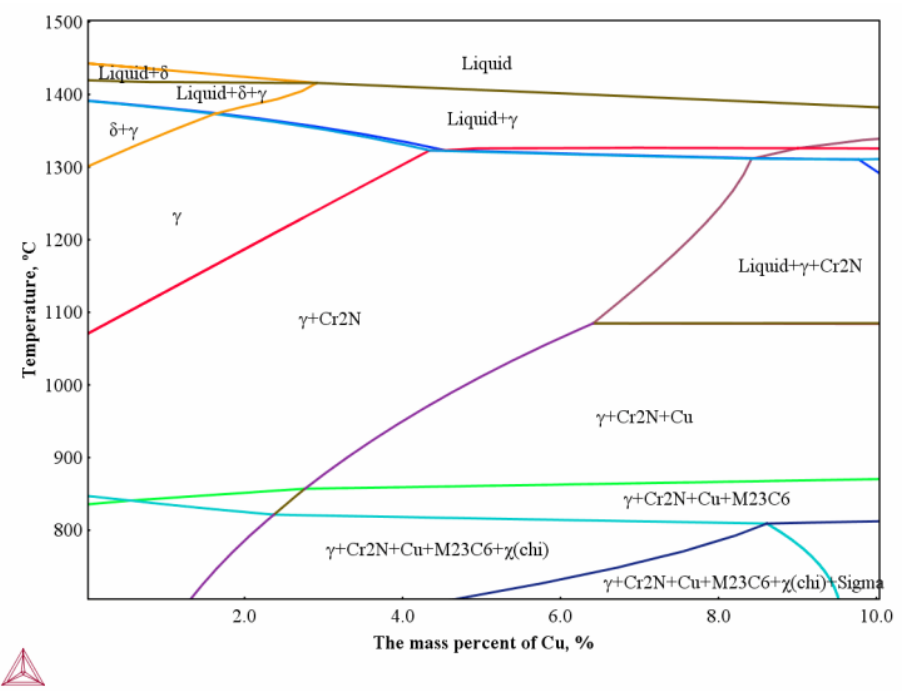

Figure 2. Equilibrium phase diagram of tested alloy calculated by Thermo-calc.

Figure 3a,b shows the optical micrograph and XRD patterns, respectively, of the sample in the solution state. Thus, it can be seen that the microstructure is full of austenite in accordance with the result of the calculation by Thermo-calc. 

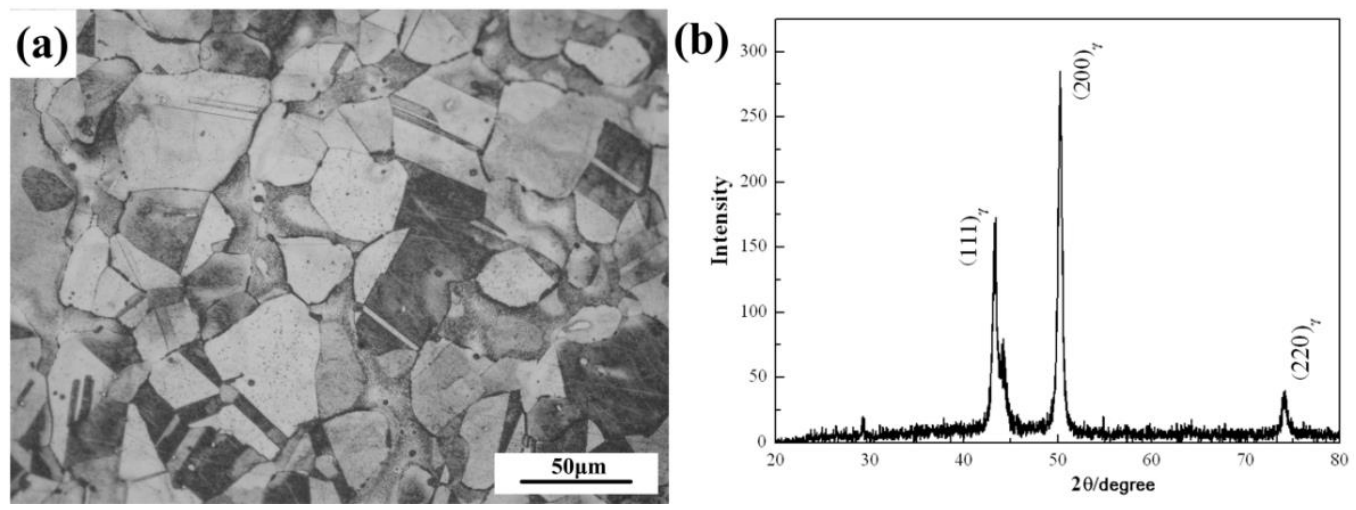

Figure 3. Optical micrograph and X-ray diffraction patterns of the sample in the solution state.

\subsection{Effect of Strain on Microcracks}

Based on the schematic diagrams shown in Figure 1, the hot compression tests were carried out to simulate the hot rolling process. Figure 4 shows the development of microcracks at $1150{ }^{\circ} \mathrm{C}$ during the hot deformation process. It can be seen that no microcracks form in the samples compressed at the strain of 0.2, but the discontinuous segregation of precipitates appears, as shown in Figure 4a. When the strain reaches 0.5 , apparent microcracks nucleate, coalesce and propagate, as shown in Figure $4 \mathrm{~b}$, and eventually evolve into microcracks.

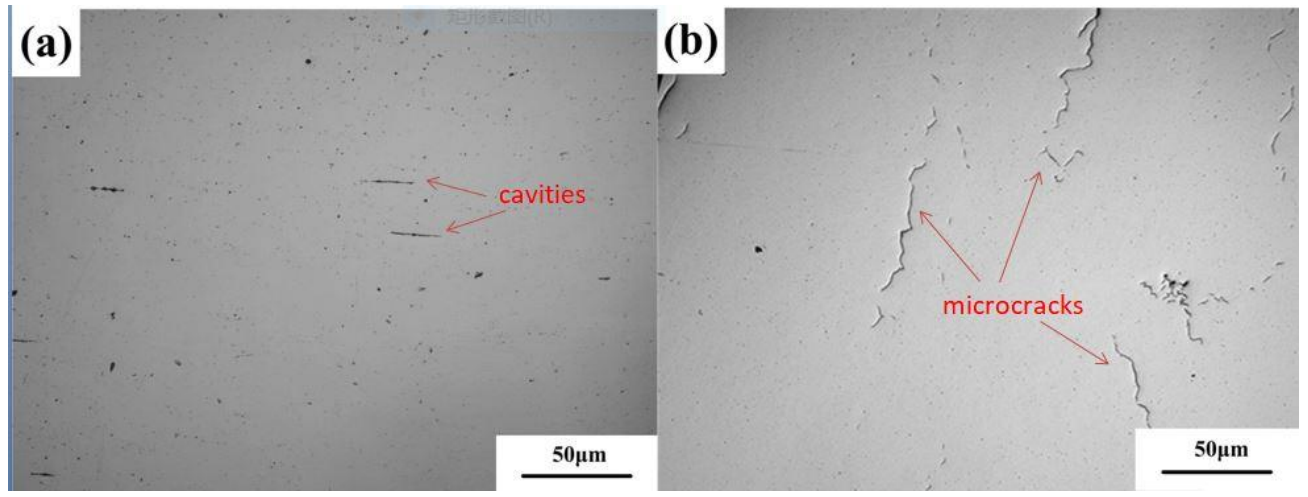

Figure 4. Development of microcracks during the hot compression process at $1150^{\circ} \mathrm{C}$. (a) $\varepsilon=0.2$, (b) $\varepsilon=0.5$.

To further study the formation mechanism of microcracks, field emission scanning electron microscopy (FESEM) with energy dispersive spectroscopy (EDS) was used to elucidate the origins of microcrack formation. Figure 5a shows a SEM micrograph of the precipitates for the Cu-bearing austenite stainless steel after the hot compression test with the strain of 0.2 at $1050{ }^{\circ} \mathrm{C}$; it can be seen that no cracking occurs. Figure $5 \mathrm{~b}$ shows the EDS-X-ray maps corresponding to Figure $5 \mathrm{a}$. Through the examination of the EDS-X-ray maps of C, S and Si shown in Figure 5f,g,h, respectively, these precipitates are identified as carbide and oxide inclusions, and no apparent $\mathrm{Cr}$-rich and $\mathrm{Cu}$-rich zone is observed(Figure $5 \mathrm{~d}$,e). To further illustrate the distribution of $\mathrm{Cu}$ in deformed materials, a SEM-EDS elemental line-scan map is obtained in the process of hot deformation at the strain of 0.2 , with the results shown in Figure 6a. It can be seen from the maps of Figure $6 \mathrm{~b}$ that the peak and trough values of $\mathrm{Cu}$ show little difference with the change in the distance. The values of vibration are almost the same and are approximately in the range of 1-2 $\mu \mathrm{m}$, which accounts for the homogeneous $\mathrm{Cu}$ distribution along the line and the possibility of the dispersed distribution of the particles. 


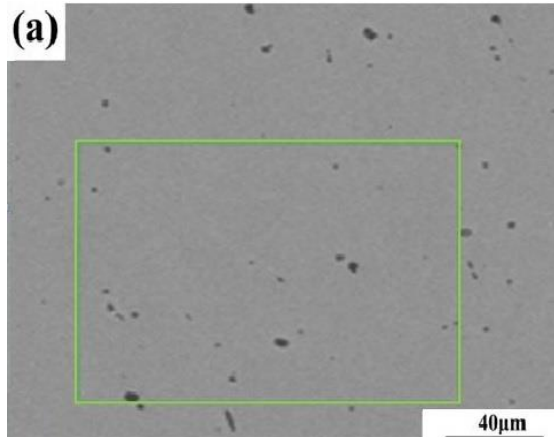

(b)
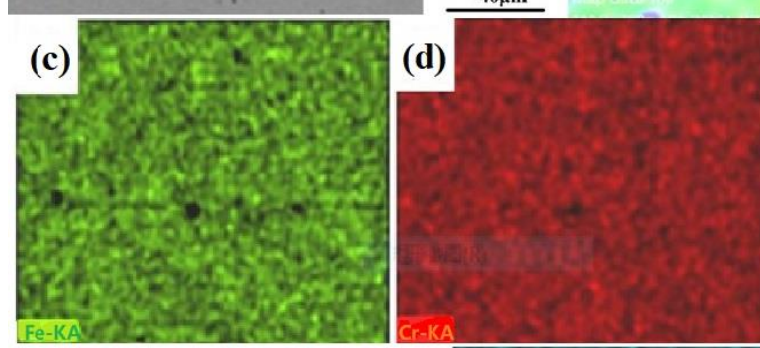

\section{回 网 圆}

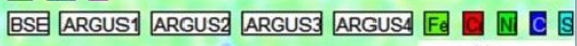

\section{(f)}

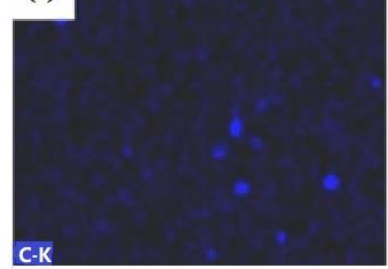

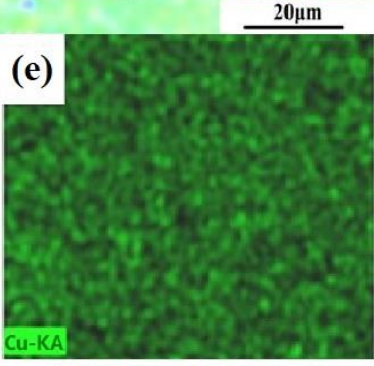

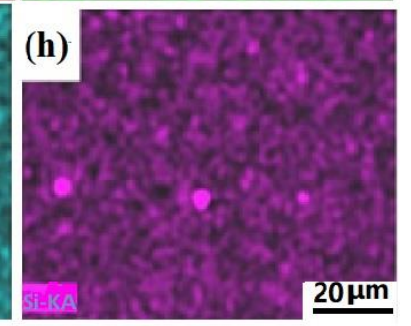

Figure 5. SEM image and EDS maps of elements with the strain of 0.2 at $1050{ }^{\circ} \mathrm{C}$.
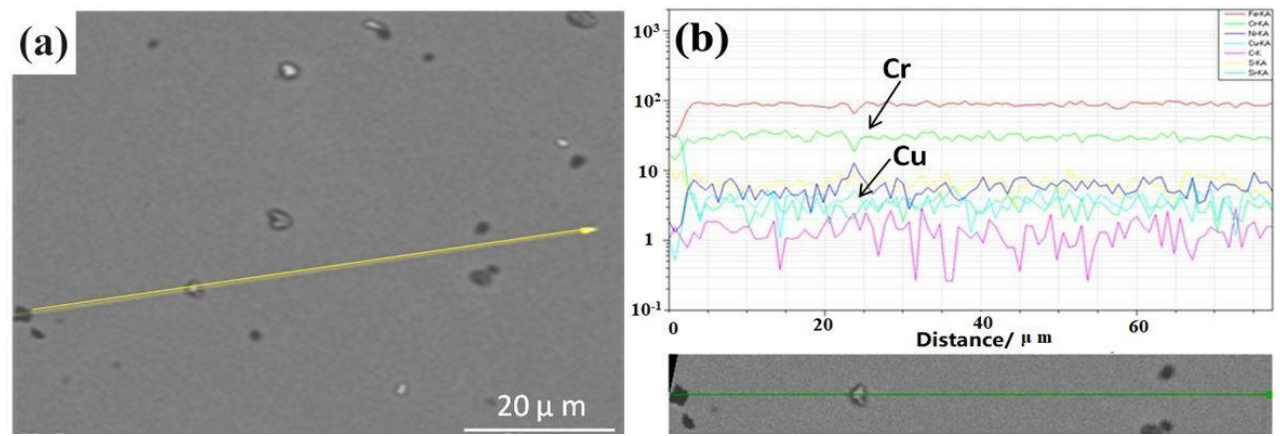

Figure 6. SEM-EDS elemental line-scan map during hot deformation with the strain of 0.2 at $1050{ }^{\circ} \mathrm{C}$.

(a) line-scan map, (b) line-scan EDS.

From the standpoint of fracture mechanics, the formation of microcracks is closely related to the second-phase particles and precipitates contained in steel. The second-phase inclusions contained in the material induce a cavity that nucleates, grows, and polymerizes until it is connected to the macroscopic cracks, and this process is considered to be the root cause of the crack propagation and the fracture of the material. With the strain reaching 0.5 , the nucleation and propagation of microcracks arises. Figure 7 a shows the area of cavity formation and aggregation, in which many small cavities in the left and a cavity after aggregation are marked, and a SEM-EDS elemental line-scan map is carried out along a line. It can be seen from Figure $7 \mathrm{~b}$ that the $\mathrm{Cr}$-rich areas appear around cavities and the distribution of $\mathrm{Cu}$ along the line is inhomogeneous. The peak and trough values of $\mathrm{Cu}$ show large differences, and a chromium-depleted zone appears in the middle. It can be seen from the above phenomena that the rich-Cu phase increases with the strain increasing, and the chromium-rich zone is generated due to the $\mathrm{Cr}(\mathrm{C}, \mathrm{N})$ precipitates in the grain boundary. 


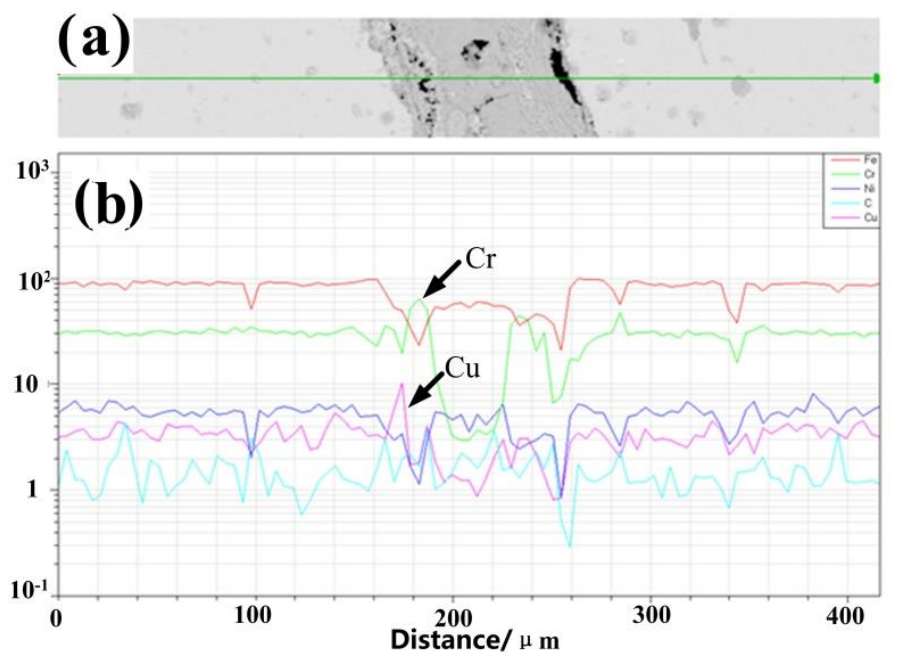

Figure 7. SEM-EDS elemental line-scan map during hot deformation with the strain of 0.5 at $1050{ }^{\circ} \mathrm{C}$.

(a) line-scan map, (b) line-scan EDS.

The dislocations and the twin crystals of the samples deformed at $1050{ }^{\circ} \mathrm{C}$ are shown in Figure 8. Various dislocation configurations, including free dislocations, dislocation walls and twins, were observed in deformed grains, further confirming that the dislocations also play an important role in crack formation. However, as shown in Figure 8a, for the sample deformed with the strain of 0.2 at $1050{ }^{\circ} \mathrm{C}$, the dislocation walls are observed obviously, and there are fewer free dislocations. While deformed at the strain of 0.5 , it is difficult for the dislocations to move, and stress concentration becomes severe. The twins are observed as a complement to slip at the stress concentration zone (Figure 8b).

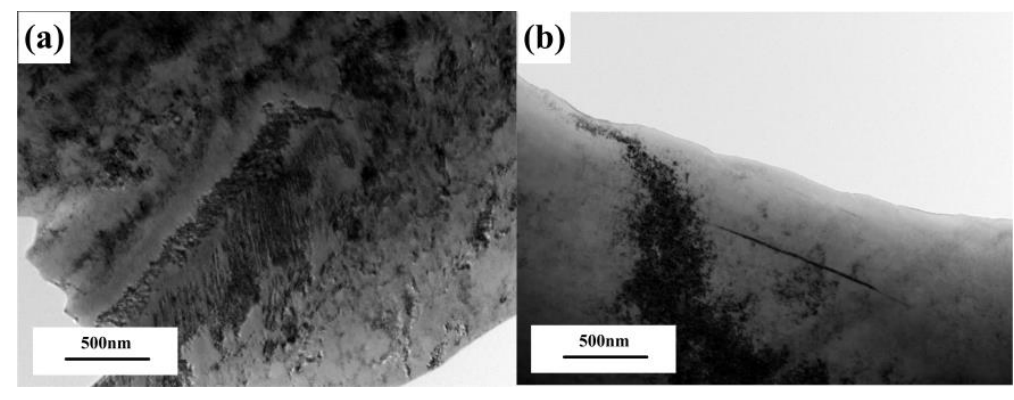

Figure 8. TEM micrograph of the samples deformed at $1050{ }^{\circ} \mathrm{C}$ and different strains of (a) 0.2 and (b) 0.5 .

Yeli and Auger [15] have proposed that $\mathrm{Cr}_{2} \mathrm{~N}$ precipitates out in advance around the grain boundary, offering the inhomogeneous nucleation location for $\mathrm{Cu}$. The $\mathrm{Cu}$-rich precipitates increase in the deformation process, and some $\mathrm{Cu}$ nucleates around $\mathrm{Cr}_{2} \mathrm{~N}$ distributed in the grain boundary, leading to the segregation of $\mathrm{Cu}$ and weakening of the grain boundary. As shown in Figure 9, regions $\mathrm{A}$ and $\mathrm{C}$ are the grain boundaries, and $\mathrm{B}$ is the region inside the grain. The copper content is $6.4 \mathrm{wt} . \%$ in region $\mathrm{A}, 5.5 \mathrm{wt} . \%$ in region $\mathrm{B}$ and $6.1 \mathrm{wt} . \%$ in region $\mathrm{C}$, from which it can be seen that the $\mathrm{Cu}$ content in the grain boundary is higher than that of $\mathrm{Cu}$ inside the grain. On the other hand, it is also revealed that the intercrystalline crack formation is related to intercrystalline $\mathrm{Cr}_{2} \mathrm{~N}$ precipitation [16]. When hot deformation is conducted, dislocations move along the slip plane. Nevertheless, intercrystalline $\mathrm{Cr}_{2} \mathrm{~N}$ hinders the dislocation movement, leading to dislocation pile-up and stress concentration. Therefore, microcracks arise during hot compression due to the synergistic effect of intergranular $\mathrm{Cu}$-rich and $\mathrm{Cr}_{2} \mathrm{~N}$ precipitation. According to literature 17, Nitrogen is detected exclusively in the form of $\mathrm{CrN}^{+}$by APT, the interconnected structure displayed is possibly due to the migration of $\mathrm{N}$ to dislocations and matrix defects, which explains the results of the experiment. 

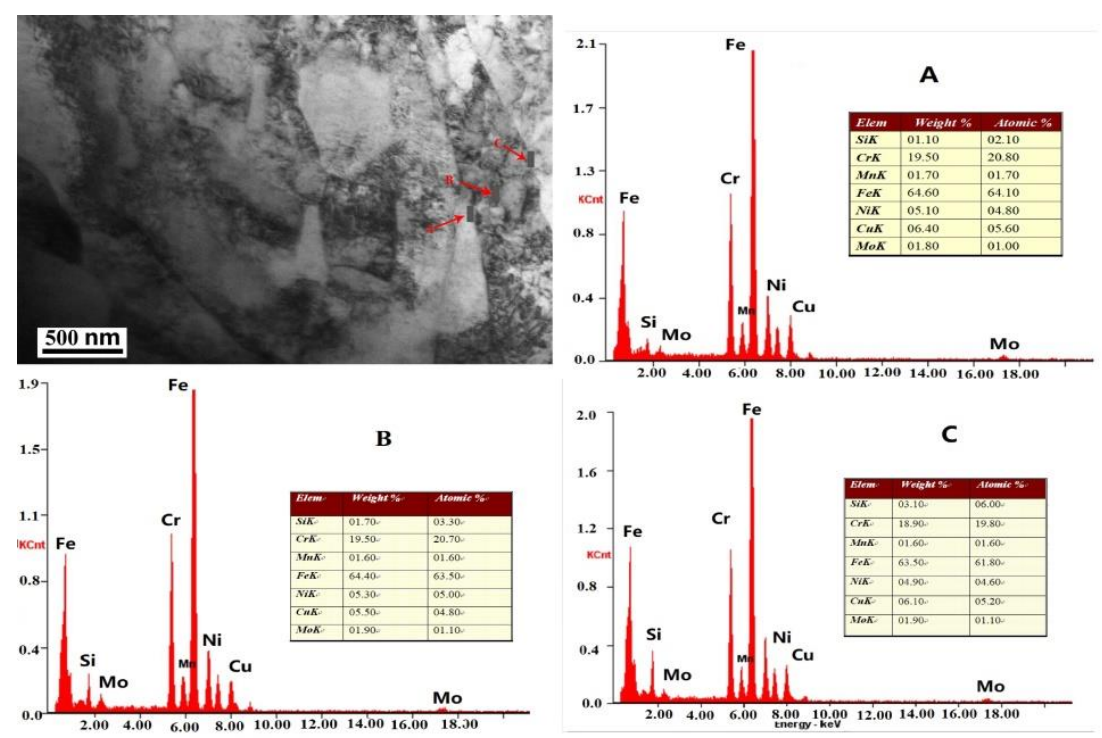

Figure 9. TEM microstructure and EDS spectra of the sample in regions A, B and C with the strain of 0.5.

\subsection{Effect of Deformation Temperature on Microcracks}

To further study the origin of crack formation, hot compression tests were carried out for the Cu-bearing austenite stainless steel at the strain of 0.5 and temperature range of $1050-1200{ }^{\circ} \mathrm{C}$.

The samples were cut along the direction perpendicular to the axial direction and polished. It can be seen from Figure 10 that a large number of cracks in the interior of the sample occur at the deformation temperature of $1100{ }^{\circ} \mathrm{C}$, while less quantity is observed at other temperatures.

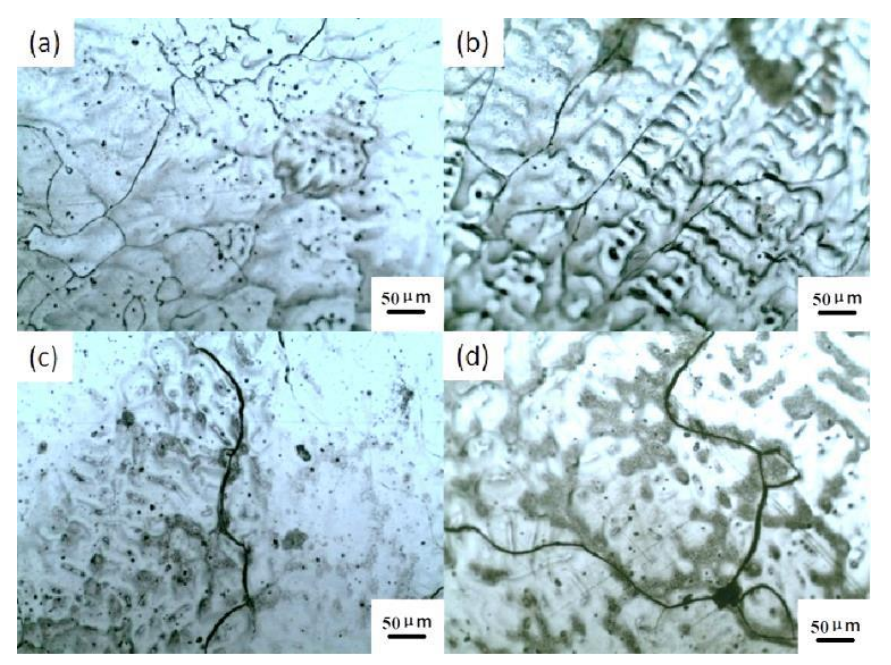

Figure 10. Diagram of profile of tested steel hot compression specimen. (a) $1050{ }^{\circ} \mathrm{C}$, (b) $1100{ }^{\circ} \mathrm{C}$, (c) $1150{ }^{\circ} \mathrm{C}$, (d) $1200{ }^{\circ} \mathrm{C}$.

From the microscopic point of view, the formation of cracks is strongly related to the precipitation of the second phase. However, conditions of undeformed austenite are close to those of homogeneous nucleation. The driving force of precipitation is only the supersaturated energy of micro-alloying elements in austenite, and carbon nitrides can be hardly obtained in actual production. Nevertheless, the strain accelerates the precipitation process of strain-induced precipitation. After the hot deformation at the different strains was investigated, it was necessary to investigate the element distribution of the samples under different deformation temperatures. Figure 11 shows the SEM images of the microcrack zones and the cavity zones obtained by hot deformation at the different 
temperatures. In addition, the elements are analyzed by EDS-X-ray maps. The result in Figures 12-14 represent the distributions of $\mathrm{Cu}, \mathrm{Cr}$, and $\mathrm{C}$, respectively, in the zone marked in Figure 11 . It can be seen that $\mathrm{Cu}$-rich, $\mathrm{Cr}$-rich and carbide phases appear in the microcrack and cavity areas and increase with the increase in the temperature of the hot compression process.

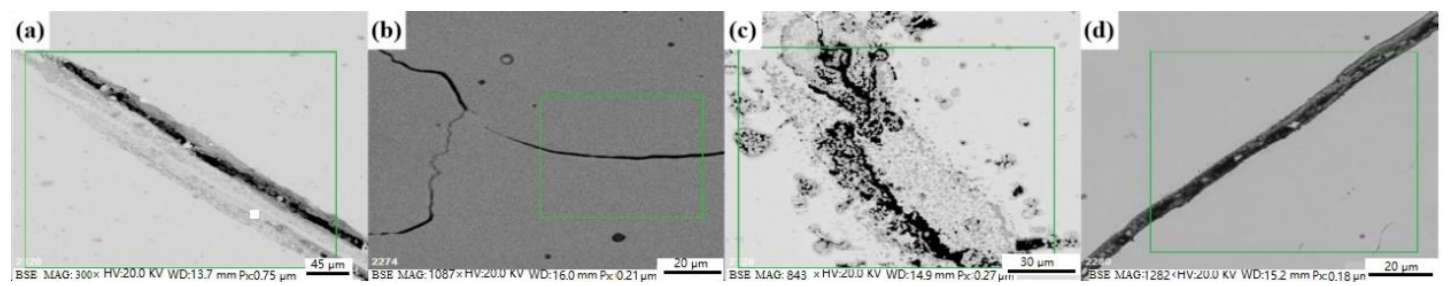

Figure 11. SEM images of the microcrack zone produced on the interior of the samples with the strain of 0.5 at different temperatures. (a) $1050{ }^{\circ} \mathrm{C}$, (b) $1100{ }^{\circ} \mathrm{C}$, (c) $1150{ }^{\circ} \mathrm{C}$, (d) $1200{ }^{\circ} \mathrm{C}$.

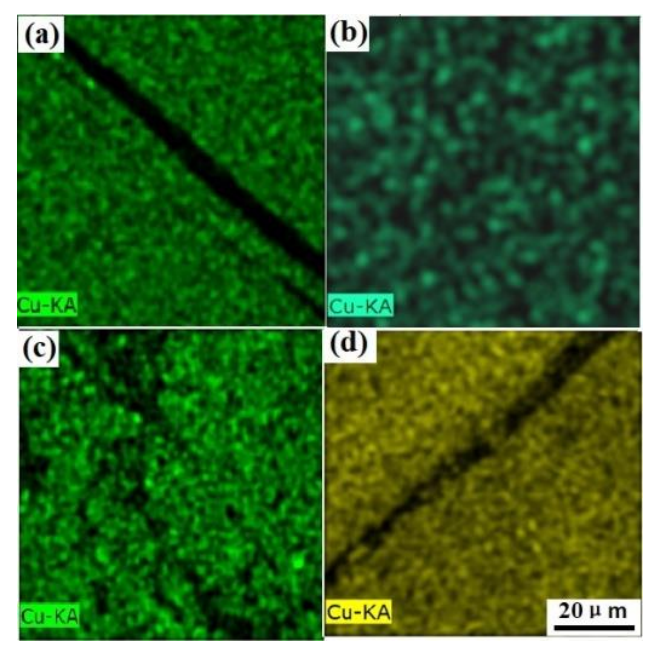

Figure 12. Copper element distribution in the microcrack zone at different temperatures (a) $1050{ }^{\circ} \mathrm{C}$, (b) $1100{ }^{\circ} \mathrm{C}$, (c) $1150{ }^{\circ} \mathrm{C}$, (d) $1200^{\circ} \mathrm{C}$.

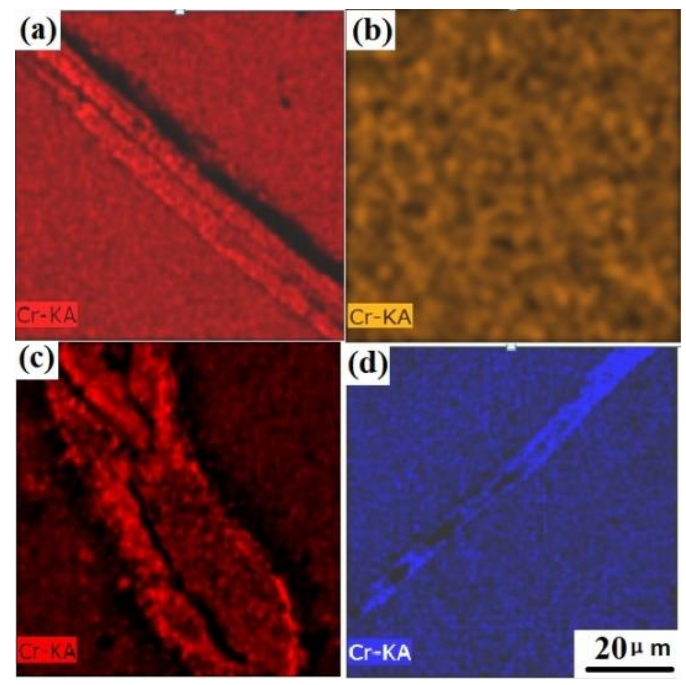

Figure 13. Chromium element distribution in the microcrack zone at different temperatures (a) $1050{ }^{\circ} \mathrm{C}$, (b) $1100{ }^{\circ} \mathrm{C}$, (c) $1150{ }^{\circ} \mathrm{C}$, (d) $1200{ }^{\circ} \mathrm{C}$. 


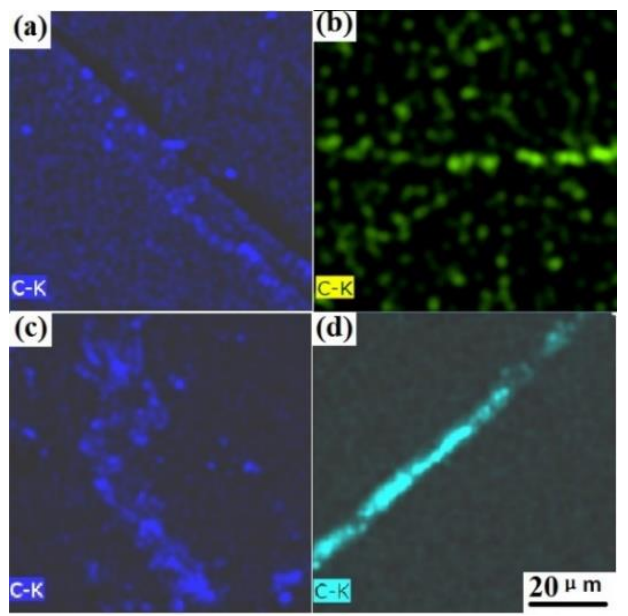

Figure 14. Carbon element distribution in the microcrack zone at different temperatures (a) $1050{ }^{\circ} \mathrm{C}$, (b) $1100{ }^{\circ} \mathrm{C}$, (c) $1150{ }^{\circ} \mathrm{C}$, (d) $1200{ }^{\circ} \mathrm{C}$.

EBSD analysis of the test specimens with the strain of 0.5 at $1100{ }^{\circ} \mathrm{C}$ (Figure 15a) shows that the compressed sample has a plastic deformation zone on the cut surface. Micropores can easily form, expand, and link with each other in this region, leading to crack propagation. Figure $15 \mathrm{~b}$ shows that a very small amount of ferrite forms, it is possible to be $\delta$-ferrite formed during the hot rolling process, which easily distributes along the grain boundary in the plastic deformation zone being prone to crack propagation along the ferrite. Figure 15c shows coincidence site lattice (CSL) distribution, it means that the low-angle $\Sigma 3$ grain boundary accounts for more than $66 \%$, the grain boundary energy is low, and it is easy to form cracks in the compression process.
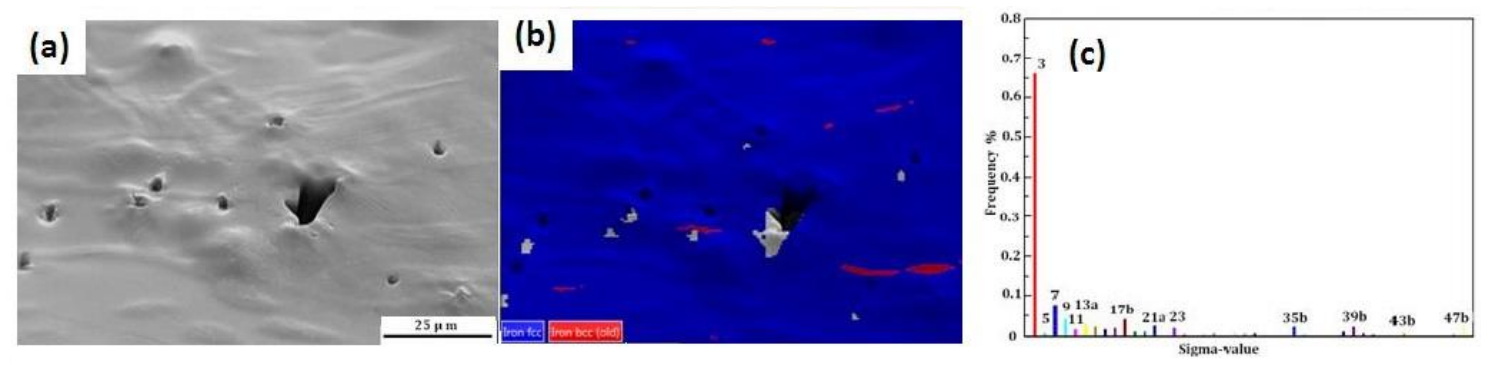

Figure 15. SEM and EBSD images of the microcrack zone produced on the interior of the samples with the strain of 0.5 at $1100{ }^{\circ} \mathrm{C}$. (a) electronic image; (b) phase distribution; (c) CSL distribution data.

The actual cracked sample rolling at $1100{ }^{\circ} \mathrm{C}$ was taken, and TEM analysis was performed. Block precipitates along the grain boundary in the Figure 16a were a composite of carbide, and the combined transmission analysis (selected area electron diffraction, SAED) showed mainly $\mathrm{M}_{23} \mathrm{C}_{6}$ carbide in the Figure 16b.

The elements mainly precipitate in the form of the Cu-rich phase and the $\operatorname{Cr}(\mathrm{C}, \mathrm{N})$ phase, which weaken the grain boundary so that the cavities form around the second phase. Meanwhile, the inclusions hinder dislocation movement, and the dislocation pile-up is generated, which leads to the concentration of stress. The stress concentration results in cavity aggregation and growth, and eventually the microcracks form. The microcrack extension under large strain leads to the fracture of materials. However, it can be seen from Figure 10 that the most cracks occur at $1100{ }^{\circ} \mathrm{C}$, and the least number of cracks is observed at higher temperature and at lower temperature. That is mainly because an increased temperature accelerates the velocity of the dislocations and reduces the stress concentration phenomenon caused by the dislocation pile-up. Furthermore, the second phase seldom precipitates at a lower temperature during the process of deformation, and few cavities are formed. When the hot compression temperature is higher, the speed of the dislocations increases, and the stress 
concentration phenomenon due to dislocation pile-up is weakened. Briefly, the macroscopic cracks decrease at lower and higher temperatures in the hot deformation process.

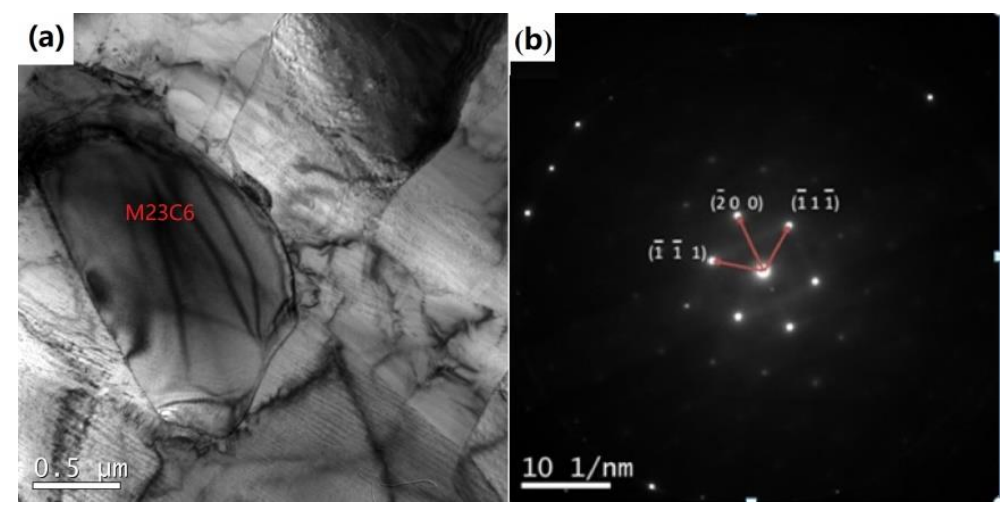

Figure 16. TEM micrograph of $\mathrm{M}_{23} \mathrm{C}_{6}$ precipitates and their SAED. (a) bright field, (b) SAED.

To further study the relationship of second phase precipitation and the microcrack formation, the external stress $\sigma$ required in the process of cavity formation around the second-phase particles is introduced, and its expression is obtained as [17]:

$$
\sigma=\frac{1}{q}\left(\frac{E \gamma_{s}}{\alpha}\right)^{\frac{1}{2}}+\frac{\sigma_{s}}{q}\left(\frac{\Delta V}{V}\right)^{\frac{1}{2}}
$$

where $q$ is the average stress concentration factor around the second phase, $E$ is the elastic modulus of the matrix, $\gamma_{S}$ is the specific surface energy of the matrix, $\sigma_{\mathrm{S}}$ is the yield strength of the matrix, and $\alpha$ is the proportionality coefficient and its value in the steel is $0.5 . V$ is the volume of the second-phase particles, and $\Delta V$ is the volume of the plastic deformation zone of the matrix around the second-phase particles. Equation (1) shows that the required stress is inversely proportional to the precipitate size. The stress that cavity formation has is unrelated to the shape of the second phase, but rather, mainly depends on size. Cavities are more likely to form around the second phase with large dimensions. The $\mathrm{Cu}$-rich precipitates, carbides and nitrides increase with the increase in strain, and the external stress $\sigma$ required in the process of forming cavities decreases, making it easy to form cavities. Furthermore, the deformation temperature and strain rate have a significant influence. A relatively low temperature can give rise to a rapid increase in the yield strength $\sigma_{\mathrm{S}}$ due to the slow movement of dislocations under the low temperature, when the strain rate reaches a constant value. According to Equation (1), the external stress $\sigma$ increases.

According to the energy consumption analysis method of the crack propagation process, the fracture toughness of materials $G_{\mathrm{IC}}$ is obtained [17]:

$$
G_{\mathrm{IC}}=2 \gamma_{\mathrm{s}}+\gamma_{\mathrm{p}}
$$

where $\gamma_{S}$ is the specific surface energy of the matrix, and $\gamma_{\mathrm{p}}$ is the consumed plastic energy during the formation of the microcracks per unit area. Because of the poor toughness for most second phases compared to the matrix, it is impossible for plastic deformation to occur, which restricts the size of the plastic zone near the crack tip; therefore, $\gamma_{p}$ decreases, and crack propagation is promoted through the formation, growth and coalescence of cavities. Hence, the increase in the second phase and inclusion volume fraction is detrimental to the fracture toughness of materials. In addition, the size, shape and distribution of the precipitates have a remarkable influence on the fracture toughness. Furthermore, the existence of segregation element weakening of the grain boundary significantly reduces the strength of the interface and the binding force of both sides of the crystal interface but has no obvious influence on the yield strength of materials. Fracture plastic energy $\gamma_{p}$ of the 
micro-zone adjacent to the interface is so low that it is easy for microcracks to form and extend along the grain boundary, thus significantly reducing the tensile strength. In this experiment, it is clearly observed that with the strain of 0.5 at each temperature, microcracks exist along the grains and extend through the grain boundary, destroying the microstructure, resulting in the material failure. The reason is that most intergranular fractures are brittle fractures, and the toughness is low, which is due to the element segregation, the second phase and stress concentration interaction with weakening the grain boundary.

\section{Conclusion}

From the study of the cracks formed in the hot deformation process with different strains and deformation temperatures, the following conclusions can be drawn:

(1) It can be seen from the calculation result obtained using Thermo-calc that $\mathrm{Cu}$ dissolves in the matrix in elemental form.

(2) The phenomenon of neucleation and propagation for microcracks is obvious. Meanwhile, $\mathrm{M}_{23} \mathrm{C}_{6}$ precipitates along the grain boundaries, causing the segregation of chromium at the grain boundaries and enrichment of $\mathrm{Cu}$ and $\mathrm{Cr}$ due to the increasing strain weakening the grain boundary, as is found by TEM and SEM examination of the microstructure.

(3) The formation of the second phase and stress concentration are the origins of microcrack formation. It is seen from the TEM examination of the morphology that the dislocation walls appear at the strain of 0.2 , while the twin crystals form in the stress concentration zone at the strain of both 0.2 and 0.5 .

(4) Due to the precipitation of the second phase and the dislocation movement, the amount of macroscopic crack is lower at high and low temperatures and is higher at $1100{ }^{\circ} \mathrm{C}$.

Author Contributions: X.-Y.F. and P.-C.B. conceived and designed; X.-Y.F. performed the experiments; X.-Y.F. and P.-C.B. analyzed the data; J.-C.Y. also put forward some suggestions and contributed reagents/materials/analysis tools; P.-c.B. also analyzed the image of transmission electron microscope; X.-Y.F. wrote the paper and P.-C.B. carried out the examination of papers.

Acknowledgments: This work was supported by the National Natural Science Foundation of China Nos. 51364031, 11672140 and 11362014.

Conflicts of Interest: The authors declare no conflict of interest.

\section{References}

1. Jiang, J.; Xu, D.; Xi, T.; Shahzadz Babar, M.; Saleem Khan, M.; Zhao, J.; Fan, X.; Yang, C.; Gu, T.; Yang, K. Effects of aging time on intergranular and pitting corrosion behavior of Cu-bearing 304L stainless steel in comparison with 304L stainless steel. Corros. Sci. 2016, 113, 46-56. [CrossRef]

2. Jin, X.; Mu, P. Targeting breast cancer metastasis. Breast Cancer 2015, 9, 23-34. [CrossRef] [PubMed]

3. Chai, H.W.; Guo, L.; Wang, X.T.; Fu, Y.P.; Guan, J.L.; Tan, L.L.; Ren, L.; Yang, K. Antibacterial effect of 317L stainless steel contained copper in prevention of implant-related infection in vitro and in vivo. J. Mater. Sci. Mater. Med. 2011, 22, 2525-2535. [CrossRef] [PubMed]

4. Lo, K.H.; Shek, C.H.; Lai, J.K.L. Recent developments in stainless steels. Mater. Sci. Eng. R Rep. 2009, 65, 39-104. [CrossRef]

5. Yamamoto, A.; Ashiura, T.; Kamisaka, E. Mechanism of improvement on corrosion resistance by copper addition to ferritic stainless steels. Corros. Eng. 1986, 35, 448-454. [CrossRef]

6. Zhou, W.H.; Guo, H.; Xie, Z.J.; Shang, C.J.; Misra, R.D.K. Copper precipitation and its impact on mechanical properties in a low carbon microalloyed steel processed by a three-step heat treatment. Mater. Des. 2014, 63, 42-49. [CrossRef]

7. Holcomb, G.R.; Alman, D.E.; Bullard, S.B.; Covino, B.S.; Cramer, S.D.; Moroz, M.Z. Ultra-Super Critical Steam Corrosion. In Proceedings of the 17th Annual Conference on Fossil Energy Materials, Baltimore, MD USA, 22-24 April 2003. 
8. Chi, C.Y.; Dong, J.X.; Liu, W.Q.; Xie, X.S. 3DAP Investigation of precipitation behavior of Cu-rich phase in Super304H heat resistant steel. Acta Metall. Sin. 2010, 46, 1141-1146. [CrossRef]

9. Yang, Y.; Cheng, S.C.; Yang, G. Effect of Cu Addition on the Creep rupture Properties of Super304H steel. Mater. Mech. Eng. 2002, 26, 23-25.

10. Nachtrab, W.T.; Chou, Y.T. Grain boundary segregation of copper, tin and antimony in C-Mn steels at $900{ }^{\circ} \mathrm{C}$. J. Mater. Sci. 1984, 19, 2136-2144. [CrossRef]

11. Fisher, R.M.; Szirmae, A.; Kamdar, M.H. ADA145889; Army Armament Research and Development Center, Large Caliber Weapon Systems Lab and Bent Weapon Lab: Watervliet, NY, USA, 1984.

12. Nakashima, K.; Imakawa, K.; Futamura, Y.; Tsuchiyama, T.; Takaki, S. Effect of copper addition on grain growth behavior of austenite in low carbon steels. Mater. Sci. Forum 2004, 467, 905-910. [CrossRef]

13. Xi, T.; Shahzad, M.B.; Xu, D.; Zhao, J.; Yang, C.; Qi, M.; Yang, K. Copper precipitation behavior and mechanical properties of $\mathrm{Cu}$-bearing 316L austenitic stainless steel: A comprehensive cross-correlation study. Mater. Sci. Eng. A 2016, 675, 243-252. [CrossRef]

14. Alaneme, K.K.; Hong, S.M.; Indrani, S.; Fleury, E.; Ramamurty, U. Effect of copper addition on the fracture and fatigue crack growth behavior of solution heat-treated SUS $304 \mathrm{H}$ austenitic steel. Mater. Sci. Eng. A 2010, 527, 4600-4604. [CrossRef]

15. Guma, Y.L.; Maria, A.A.; Keith, W.; George, D.W.S.; Paul, A.J.B.; Michal, P.M. Sequential nucleation of phases in a 17-4PH steel: Microstructural characterisation and mechanical properties. Acta Mater. 2017, 125, $38-49$.

16. Moon, J.; HoLee, T.; HoShin, J.; WookLee, T. Hot working behavior of a nitrogen-alloyed Fe-18Mn-18Cr-N austenitic stainless steel. Mater. Sci. Eng. A 2014, 594, 302-308. [CrossRef]

17. Yong, Q.L. Secondary Phases in Steels; Metallurgy Industry Press: Beijing, China, 2006; pp. 6-9.

(C) 2018 by the authors. Licensee MDPI, Basel, Switzerland. This article is an open access article distributed under the terms and conditions of the Creative Commons Attribution (CC BY) license (http:/ / creativecommons.org/licenses/by/4.0/). 